\title{
Causal Loops for Analysis of the Social Dimension to Complex Systems
}

Mark W. Milke

Department of Civil and Natural Resources Engineering, University of Canterbury, Christchurch, New Zealand

Private Bag 4800, Christchurch 8140, New Zealand; Ph. 64-3-3642-248; email:

mark.milke@canterbury.ac.nz 


\title{
Causal Loops for Analysis of the Social Dimension to Complex Systems
}

\begin{abstract}
Better methods of analysis and communication are needed to analyse civil engineering and environmental systems that have a social dimension. Causal loops are examined as a way to improve analysis. Opposition to landfills is developed to show the role that causal loops could provide in social/technical systems analysis. The example leads to a conclusion that public access to an online database of monitoring data could help reduce opposition. Causal loops are highlighted as one way in which we can reorganise our thought and use a new language to analyse our increasingly complex civil engineering and environmental systems.
\end{abstract}

Keywords: influence diagrams, cause-effect, landfill, NIMBY, social opposition.

\section{Introduction}

"Man is a prisoner of his own way of thinking, and of his own stereotypes of himself. His machine for thinking, the brain, has been programmed to deal with a vanished world. This old world was characterized by the need to manage thingsstone, wood, iron. The new world is characterized by the need to manage complexity."

Stafford Beer, Platform for Change, 1975.

We study systems in order to better manage complex problems. In civil engineering and environmental systems-- in contrast to electrical, computer, or aeronautical systems-- the management of complex problems often has a social dimension. We analyse systems where people matter-- where we need to understand why people act the way they do, how they evaluate risk, and how social institutions interact with technical systems.

We lack the language, or communication model (Elms and Brown, 2012), to analyse these problems and to communicate results. We fool ourselves if we think we are analysing social systems problems by compiling long bullet-point lists of 'influencing factors'. Similarly, an action plan of what needs to change does not help us 
see why we need to change or what has kept us from changing in the past. A major challenge for us as systems analysts is to develop tools to analyse the social dimension of civil engineering and environmental systems.

I want to use the occasion of the $30^{\text {th }}$ anniversary of Civil Engineering and Environmental Systems to reflect on the use of causal loops to help us better analyse systems that have a social dimension. A causal loop analysis forces us to think in terms of what leads to change and what leads to equilibrium. We can use this understanding to envision new ways to resolve problems at the social-technical nexus.

Causal loops, also known as influence diagrams, have a long history for analysis of both social and technical systems. In particular, I would highlight the contributions of Forrester (1968), Eden et al. (1983), Bossel (1994), and Sterman (2000). For a modern application, I would also mention Allan et al. (2008).

\section{Case study: social control of environmental impacts of landfills}

Why is there such strong opposition to landfills? With modern technology, they have little impact on the environment, they meet a number of social and environmental needs for proper solid waste management, and their cost is low. I will use this as a case study for exploring how to use causal loops to communicate an analysis.

First, we need to see that public opposition to landfills is part of a broader process of social control of environmental impact. Public opposition arises because people believe that the social system in place for control of environmental impact is not adequate. Let's start the analysis, then, by considering how social control has been expected to occur through regulatory control.

Figure 1 represents the process of regulatory control. This figure and the others here have been developed with the Vensim software (http://vensim.com). When government increases pressure to improve environmental quality of landfills, there is 
greater expenditure on control, while less pressure leads to less control. This link is ' + ' in the sense that if we had a numerical equation $y=g(x)$, where $y=$ expenditure and $x=$ government pressure, then $d y / d x$ would be greater than zero. More expenditure on control leads to improved environmental quality, while lower expenditure would be expected to lead to worse environmental quality. This link is also ' + '. Finally, better environmental quality decreases the pressure that government applies for further environmental improvements. This link also works the other way: worse environmental quality will lead to greater pressure by government for improvements. This link is '-" because, for a function $x=g(z)$ where $x=$ government pressure and $z$ is environmental quality, that $d x / d z$ is less than zero.

The overall loop in Figure 1 is a negative feedback process that leads to equilibrium. We can show this mathematically by recognising that the product of the three links is less than zero ( ' + ' * ' $+{ }^{\prime} *{ }^{\prime}{ }_{-}$' $<0$, or $d y / d x * d z / d y * d x / d z<0$ ). More expenditure improves the environment to the point where the government stops increasing regulatory pressure. Any description of a stable social arrangement must have a negative feedback process that can describe what is keeping the system from changing. Figure 1 is one way to represent a system for social control of environmental impact of landfills.

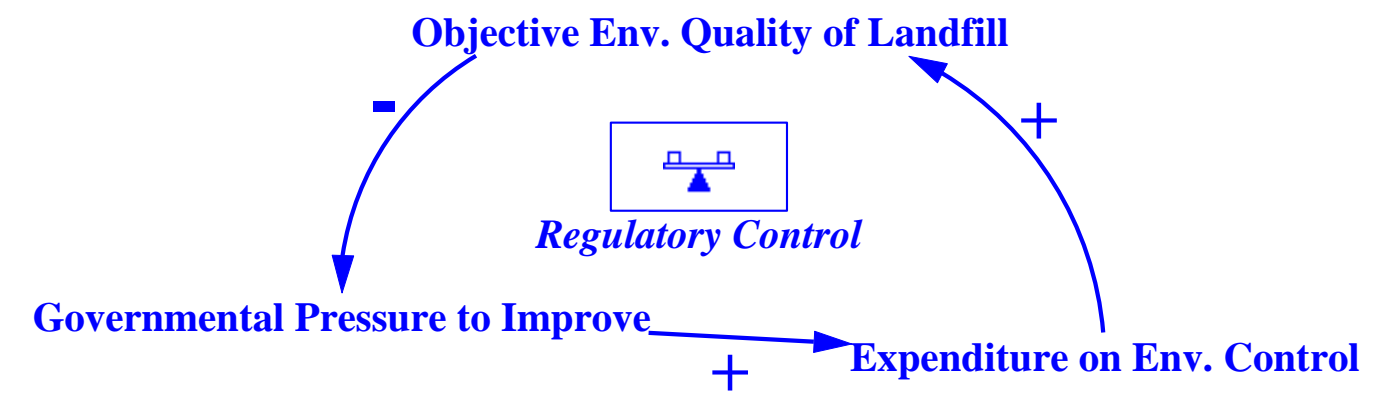


Figure 1. Causal loop for regulatory control of landfills.

Figure 2 adds a second loop to this situation. It shows how public oversight contributes to the process of social control. I have represented this process by introducing a variable called 'local perceived risk level'. This represents the importance of subjective assessment of environmental quality and distinguishes it (in a simplified way) from how government regulates based on objective measures of environmental quality. Either loop can be dominant, but whichever one dominates, an equilibrium results.

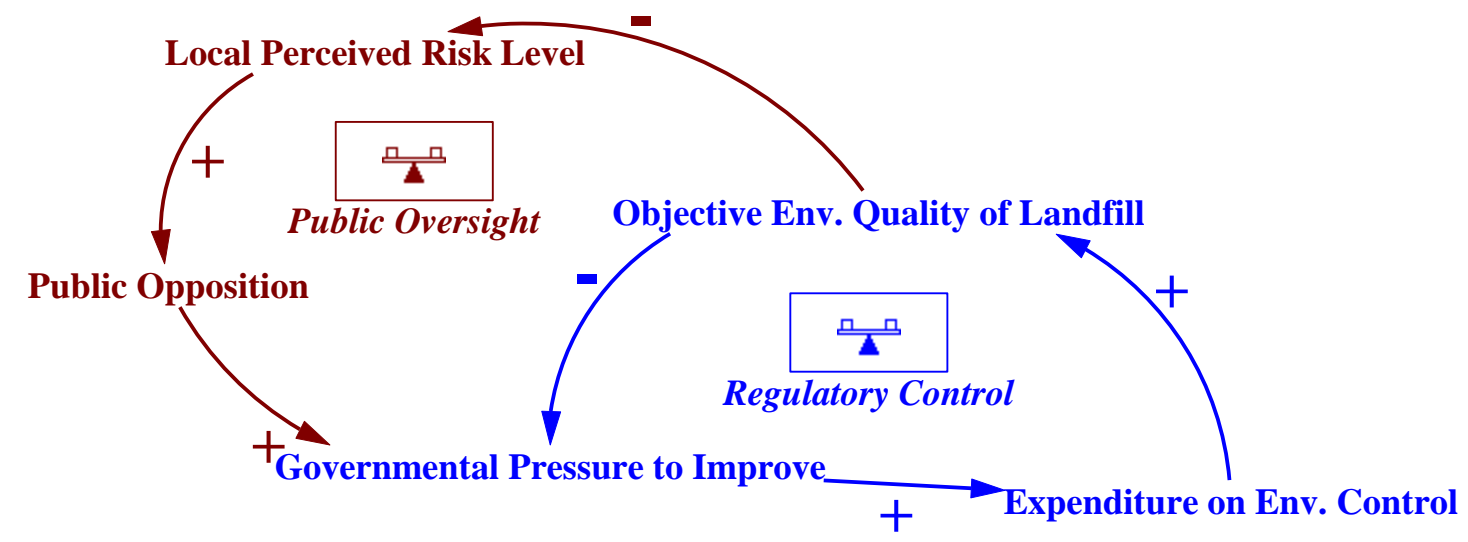

Figure 2. Causal loop showing the relationship between regulatory control and public oversight of landfills.

Figure 3 explores one response that landfill operators might take when they believe that the locally perceived risk level is leading to excessive regulation. In this response, the operators spend money on local public relations to better inform the public 
of the objective risk level. I have represented this with two new loops. In the 'Improve Image' loop, more investment in public relations leads to a decrease in perceived risk; in turn this reduces public opposition, decreasing the need for expenditure on public relations. This is an equilibrium loop because of two positive links and one negative link, as with the first loop. In this case the loop is shown as going in a clockwise direction while the others are shown as going in a counter-clockwise direction. The direction has no impact on whether it is a positive or negative feedback loop. The direction is a result only of the topology of the situation and the way that the analyst chooses to draw the relationships.

The other loop is called 'Misdirected Funds'. In this loop, there is recognition that the expenditure on local public relations decreases the ability of the operators to spend on environmental control, which could lessen the environmental quality. This, in turn, could lead to greater perceived risk, public opposition, and the expenditure of even more funds on local public relations. This is a positive feedback loop, represented by the symbol of a snowball picking up mass as it goes downhill. This positive feedback loop can be kept in check and exist in a stable system because of the presence of negative feedback loops in the system. 


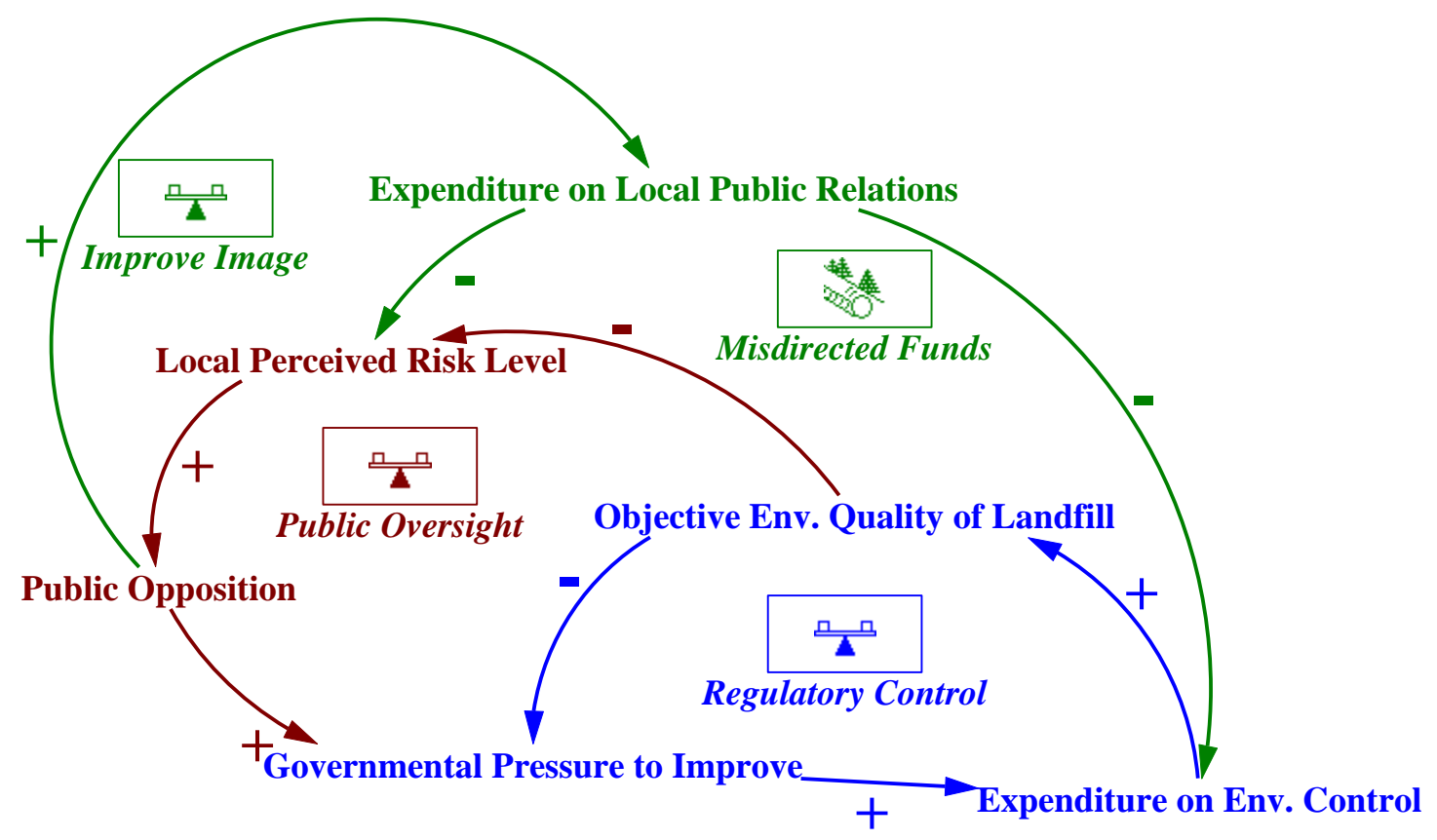

Figure 3. Casual loop introducing the response of expenditure on local public relations.

The processes represented in Figure 3 do not describe why it is that public opposition can be so strong in spite of expenditure on public relations. Figure 4 introduces another loop called 'Historical Mistrust'. This enriches the representation of the locally perceived risk level to include the influence of historical events on broader societal opinion. Figure 4 indicates that societal opinion against a landfill is negatively influenced by objective facts on environmental quality (as examples, leachate discharge to a stream or an explosion from landfill gas), though perhaps many years after the event. The addition of this loop explains both why more expenditure on local public relations may not reduce public opposition, and also why good current objective facts on environmental quality may not be enough to reduce public opposition in many cases. This loop leads to equilibrium because, over time, the improved environmental quality will change societal opposition, then local opposition, so reducing the pressure to improve. 


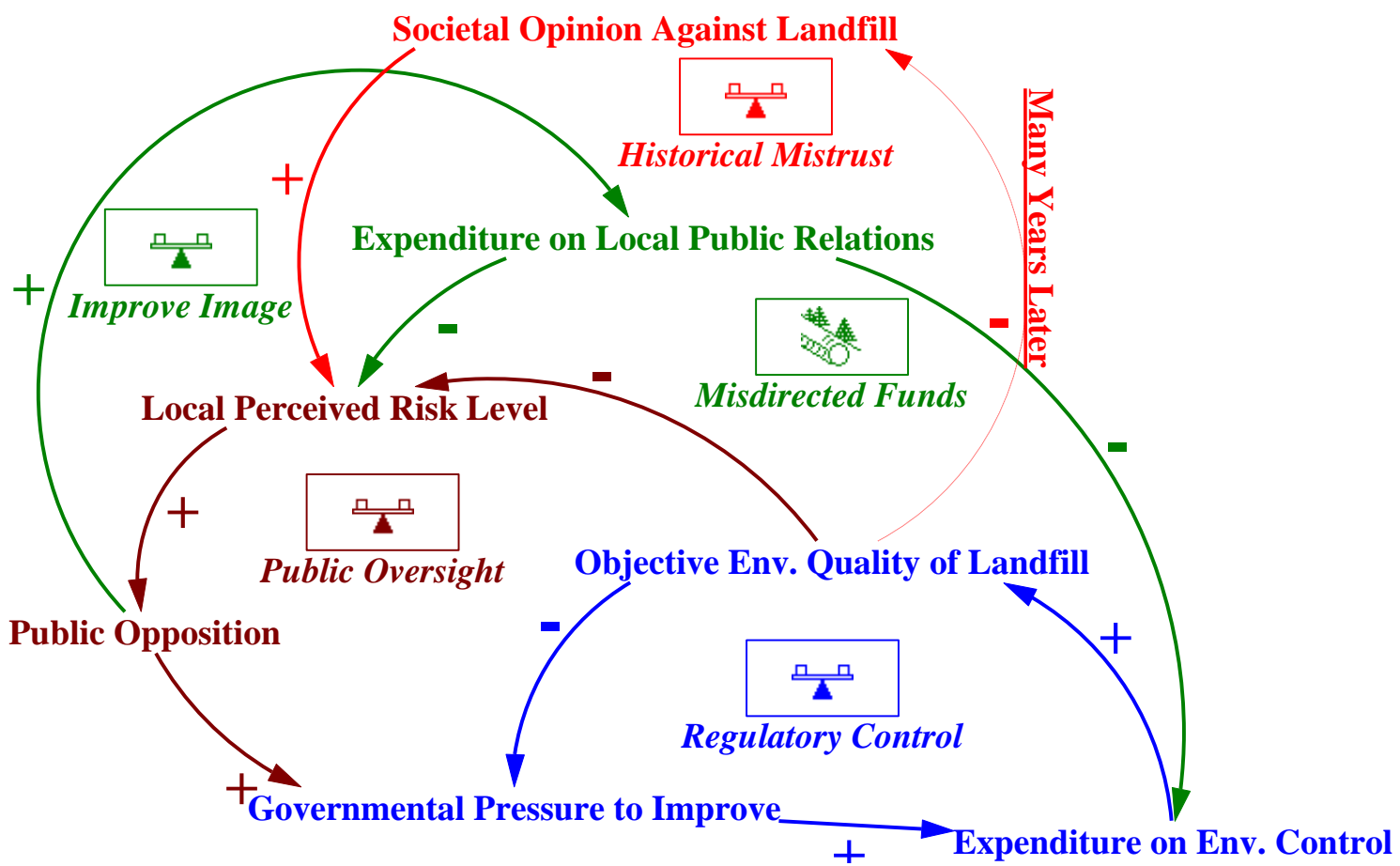

Figure 4. Causal loop introducing historical mistrust as a process.

Figure 4 will be as far as I take this analysis. People might want to dispute parts of this analysis or make additions. I think it is accurate enough and meets my purpose of describing a public-technical interface on a civil engineering and environmental system. It shows root causes and why the system is resistant to change. Figure 4 describes a situation where technical professionals, who believe there should be more emphasis on the importance of environmental quality data in determining regulatory levels, are unable to see a way to change an existing system. Once we learn and appreciate this method of communication, we have a more efficient tool for explaining a complex situation than a 20 page social analysis report would be. It highlights for us 
that another process is needed to avoid the long time delay required to overcome historical distrust.

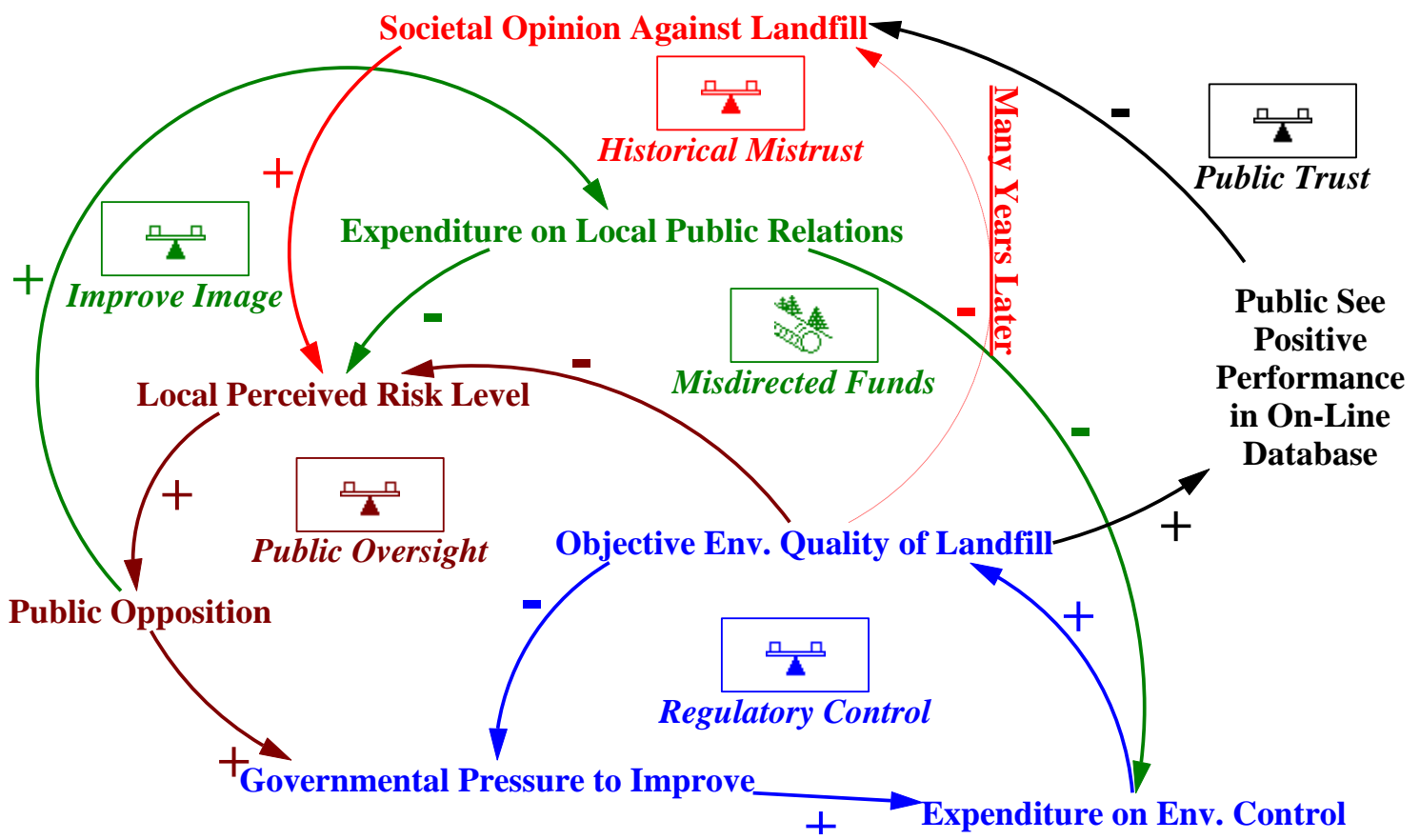

Figure 5. Causal loop showing the ability to introduce a new process to overcome the opposition to landfills arising from historical mistrust.

Figure 5 adds another process called 'Public Trust'. This process shows an anticipated response to the addition of a public, on-line database of environmental quality. If properly developed, one could imagine that a public information system of this type could decrease societal opinion against landfills. This, in turn, would decrease the local perceived risk level, allowing a greater influence of objective environmental quality, and thereby leading to less public opposition. 


\section{Discussion}

Causal loops can be valuable when analysing social processes and how they interrelate with the technical aspects of civil engineering and environmental systems. Causal loops are not easy to grasp and in effect are a different language. Getting systems analysts to understand the language is difficult; getting non-systems people to understand it is a faroff goal.

Causal loops will not help resolve problems for technical experts who do not have the capacity to analyse social problems. As individuals, we will need better understanding of risk and risk perception, and better listening skills, so we can see the links and processes at work. This relationship between complexity and communications has been highlighted recently by Elms and Brown (2012) in their analysis of communication models.

Once we have that understanding, causal loops can help us to better analyse civil engineering and environmental systems. Causal loops can help us to better communicate complexity. They are just one example of the opportunities that we have to improve the analysis of civil engineering and environmental systems.

Stafford Beer, if he were here to contribute to this special issue, might say that advances in computational ability will be crucial in better management of complexity. However, he would likely add that over the next 30 years we will also need to focus on reorganisation of thought and new languages. Without these, are we not just making a more efficient treadmill?

\section{Acknowledgements}

The author wishes to acknowledge the support of the NZ-EU Opt-ALI exchange programme that allowed the author to conduct much of the work for this paper. The author also wishes to 
acknowledge the kind support of the Operations Research Group, Department of Management Engineering, Danish Technical University.

References

Allan, N. Yin, Y., Scheepbouwer, E., 2008. A study into the cyclical performance of the New Zealand construction industry. Christchurch: New Zealand Centre for Advanced Engineering.

Beer, S., 1975. Platform for change. Chichester: John Wiley and Sons.

Bossel, H., 1994. Modeling and simulation. Wellesley, MA: A.K. Peters.

Eden, C., Jones, S., and Sims, D., 1983. Messing about in problems. Oxford: Pergamon Press.

Elms, D.G., and Brown, C.B., 2012. Professional decisions: the central role of models. Civil Engineering and Environmental Systems, 28(3), 165-175.

Forrester, J., 1968. Principles of systems. Cambridge, MA: Wright-Allen Press.

Sterman, J.D., 2000. Business dynamics: systems thinking for a complex world. Boston, MA: McGraw-Hill. 